\title{
Humor e psicose em esquizofrenia: explorando fronteiras diagnósticas com o Inventário de Critérios Operacionais para Doenças Psicóticas (OPCRIT) e o caso John Nash
}

\author{
Cristiane Damacarena Martins* \\ Alexei Gil ** \\ Paulo Silva Belmonte de Abreu ${ }^{* *}$ \\ Maria Inês Lobato****
}

\section{INTRODUÇÃO}

Conhecido internacionalmente e ganhador do Prêmio Nobel de Matemática de 1994, John Nash ficou famoso recentemente quando sua história foi apresentada no filme Uma mente brilhante (em inglês, $A$ Beautiful Mind), dirigido por Ron Howard. Assistindo o filme, diferentes psiquiatras manifestaram dúvidas a respeito do diagnóstico do matemático. Seria portador de esquizofrenia, transtorno esquizoafetivo ou transtorno bipolar? Dúvidas que freqüentemente enfrentamos na nossa prática clínica.

Indivíduo de grande inteligência e criatividade, Nash apresentava crises de grave agitação, delírios de grandeza e vários sintomas bizarros. Desde sua primeira internação no Hospital McLean, em Boston, havia um

\footnotetext{
* Psiquiatra, mestranda em Clínica Médica da Faculdade de Medicina da Universidade Federal do Rio Grande do Sul (FAMED-UFRGS).

** Psiquiatra, mestrando em Psiquiatria da FAMED-UFRGS.

*** Psiquiatra, MHS, PhD, Professor Assistente do Departamento de Psiquiatria da FAMED-UFRGS (autor responsável pela correspondência).

**** Psiquiatra, doutoranda em Clínica Médica da FAMED-UFRGS.
}

consenso entre os psiquiatras de que Nash era obviamente psicótico. Nessa internação, Nash achava-se portador de capacidades ímpares. Falava de forma frenética sobre textos codificados no cabeçalho da primeira página do jornal The New York Times, os quais somente ele havia decodificado. Seu discurso era recheado de diversas histórias sobre conspirações estrangeiras, homens de gravatas vermelhas que o seguiam e alienígenas que estariam cuidando de sua carreira. Dizia ter a salvação para o universo e a missão de organizar um governo mundial, autodenominando-se "O Imperador da Antártida" e "O Príncipe da Paz". Comentava com amigos que a foto do papa João XXIII na verdade era uma foto sua retocada. Considerava-se seguido pelo FBI, que era o pé esquerdo de Deus e buscava, através de cartas escritas sem sentido, obter reconhecimento dos seus altos poderes, que, segundo ele, talvez fossem celestiais. Insone, andava descalço e expressava-se com um discurso desconexo.

Fica óbvia, numa primeira leitura, a presença de um transtorno psicótico. Porém, a presença de exaltação do humor, discurso 
frenético e delírios de grandiosidade constituem elementos adicionais que dificultam 0 diagnóstico diferencial entre as psicoses e os transtornos de humor. A característica bizarra dos delírios grandiosos em geral aponta para esquizofrenia, porém não encerra o problema diagnóstico. Nas classificações atuais mais usadas em clínica e na pesquisa, ou seja, o Manual Diagnóstico e Estatístico de Doenças Mentais (DSM-IV) ${ }^{1}$ e a Classificação de Transtornos Mentais e de Comportamento da CID-10 - Descrições Clínicas e Diretrizes Diagnósticas (CID-10) ${ }^{2}$, é importante quantificar a presença de episódios distintos de psicose e sintomas de humor e estabelecer uma hierarquia de tempo entre eles.

$\mathrm{Na}$ biografia de John Nash (escrita por Sylvia $\mathrm{Nasar}^{3}$ ) que deu origem ao filme, há um relato detalhado de todos os anos de sua vida, com uma extensa descrição de sintomas psicóticos e comportamento bizarro persistentes, freqüentemente associados a exaltação do humor e delírios de grandiosidade. A presença desses sintomas de humor seria suficiente para que se questionasse o diagnóstico de esquizofrenia que recebeu à época? E se John Nash fosse portador do transtorno esquizoafetivo? Ou quem sabe transtorno bipolar? E, se realmente se tratasse de esquizofrenia, qual subtipo seria?

Esta questão tem sido freqüentemente citada por clínicos experientes, fazendo eco aos relatos de psiquiatras sociais, clínicos e forenses, trabalhando seja em hospitais, asilos, ambulatórios, serviços de emergência, consultoria psiquiátrica ou em Centros de Atenção Psicossocial (CAPS), que se vêem diariamente expostos a dúvidas quanto à classificação dos pacientes observados. Será que é exaltação, agitação ou ambas? E os pensamentos de conteúdo grandioso, seriam acelerados ou agitados? E o comportamento de procura de contato com muitas pessoas, é a sociabilidade aumentada do maníaco ou a grandiosidade delirante do esquizofrênico? Será que um só desses sintomas pode modificar o diagnóstico? E o que fazer ao observar sintomas de energia aumentada ou tristeza durante algum período de doença? E será que a ocorrência desses sintomas define duas doenças essencialmente diferentes, ou descreve aspectos de uma doença única com diferenças contínuas ${ }^{4}$ ?

O objetivo do presente estudo é verificar, através de diferentes simulações, o efeito da presença de sintomas de humor em um indivíduo com psicose crônica sobre o diagnóstico psiquiátrico, utilizando diferentes sistemas classificatórios, especialmente o DSMIV e o CID-10, definidos por um sistema computadorizado, o Inventário de Critérios Operacionais para Doenças Psicóticas (OPCRIT, do inglês Operational Criteria Checklist for Psychotic Illness) e discutir algumas questões importantes a respeito das classificações psiquiátricas atuais.

\section{MÉTODO}

Os autores são psiquiatras pesquisadores da área de esquizofrenia, com média de prática no atendimento de pacientes psicóticos entre 8 e 25 anos e que receberam treinamento específico para o uso do OPCRIT (anexo 1).

O preenchimento do OPCRIT foi feito após leitura sistemática da biografia de John Nash na tradução para português e assistência ao filme, sendo anotados todos os sintomas presentes pelo autor com mais experiência (P.B.A.). Cada item do OPCRIT foi discutido com os demais autores, sendo definidos após consenso dos quatro. Contudo, devido à presença de sintomas inicialmente discordantes, estes foram computados em duas simulações separadas, com a verificação do diagnóstico para cada alternativa discordante do sistema.

A existência do sistema OPCRIT, já adaptado para o português e em uso no Brasil, acompanhado pela percepção de sutilezas diagnósticas complicadoras no caso John Nash, motivaram a aplicação do instrumento. A fonte de avaliação (item 1 do OPCRIT), que corresponde à maneira como foram obtidos os dados - no caso, através da biografia e do filme - recebeu cotação 6 (combinação de fontes excluindo entrevista estruturada). Essa possibilidade de combinação de fontes de avaliação já havia sido prevista pelos autores. Desta forma, é um uso possível do instrumento.

O sistema OPCRIT foi desenvolvido por McGuffin, Farmer \& Harvey em $1991^{5}$, com sua última versão em $1997^{6}$, e constitui-se de uma lista de sintomas, um glossário com as definições e cotações dos itens e programas de computadores pessoais que fornecem o diagnóstico dos sujeitos segundo as principais classificações diagnósticas em psiquiatria. Este sistema foi traduzido e validado para a língua portuguesa por pesquisadores da Universidade de Coimbra ${ }^{7,8}$ e introduzido no Brasil como parte do Projeto de Cooperação Internacional Brasil/ Portugal (CAPES - GRICES) de Estudo das 
Bases Moleculares da Esquizofrenia nas Populações Brasileira e Portuguesa ${ }^{9}$.

$O$ projeto permitiu o treinamento da equipe dos dois países para o uso do sistema OPCRIT com metodologia semelhante, tendo sido aplicado pelos autores em mais de 200 pacientes portadores de síndromes psicóticas.

O OPCRIT é dividido em 90 itens: os 16 primeiros correspondem a fatores de identificação (demográfica e clínica); os nove seguintes (do $17^{\circ}$ ao $25^{\circ}$ ) avaliam a aparência e o comportamento; os seis itens seguintes (do $26^{\circ}$ ao $31^{\circ}$ ) se referem à linguagem e à forma de pensamento; 22 itens (do $32^{\circ}$ ao 53을 dizem respeito ao afeto e a características associadas; 18 itens (do $54^{\circ}$ ao $71^{\circ}$ ) avaliam crenças e idéias anormais; seis itens (do $72^{\circ}$ ao $77^{\circ}$ ) avaliam percepções alteradas do sujeito; seis itens (do $78^{\circ}$ ao $83^{\circ}$ ) dizem respeito a abuso ou dependência de drogas; e, por último, sete itens se referem a características de entrevista (incluindo credibilidade das informações, insight e ligação com o entrevistador) e de curso da doença (incapacitação, deterioração e resposta a neurolépticos). $\mathrm{Na}$ avaliação da maioria dos sintomas, devem ser definidos o tempo de duração e sua ocorrência ao longo da doença, com o intuito de preenchimento do critério de tempo e impacto de sintomas proeminentes. Pela sua facilidade e precisão, este sistema tem sido progressivamente aplicado por diferentes grupos de pesquisa em esquizofrenia nos EUA e Europa ${ }^{10,11}$.

Os resultados do checklist obtidos após uma revisão sistemática do curso da doença com pacientes e familiares, seguidos de uma entrevista semi-estruturada baseada no glossário do programa, são depois inseridos no sistema OPCRIT e geram diagnósticos nas categorias de distúrbios psicóticos e de humor de acordo com 13 classificações diferentes:
DSM-IV (incluído em 1994), CID-10, DSM-III, DSM-III-R, RDC (Research Diagnostic Criteria, de Spitzer), Critérios de St. Louis, Critérios Flexíveis para Esquizofrenia de Carpenter, Sintomas de Primeira Ordem de Schneider, uma versão dos Critérios Franceses para Psicoses Não-Afetivas, Critérios de Taylor e Abrams e três classificações de esquizofrenia usadas em estudos genéticos, de Tsuang \& Winokur, Crow e Farmer. O sistema OPCRIT foi desenhado para ser utilizado por clínicos treinados e pode ser preenchido com base em entrevistas diagnósticas, registros médicos e outras fontes, desde que suficientemente detalhadas; além disso, ele representa um método de diagnóstico que permite a comparação entre diferentes estudos e auxilia a estruturar o processo diagnóstico.

Usamos a perspectiva de ocorrência em toda vida de sinais e sintomas devido à perspectiva desejada, ou seja, a de definir um diagnóstico principal predominante ao longo da vida. Adicionalmente, esta é a perspectiva mais utilizada em pesquisa psicopatológica e genética em esquizofrenia ${ }^{12,13}$

Devido a dúvidas e falta de consenso inicial na identificação de alguns sintomas durante o preenchimento do OPCRIT, foram montadas três simulações (tabela 1), sendo a primeira (Simulação 1) a que forneceu o resultado mais provável. As outras duas são possibilidades a serem consideradas (Simulações 2 e 3) e posteriormente servirão como elementos para discussão.

Para a obtenção do diagnóstico mais provável de John Nash (Simulação 1), foi primeiramente considerada a ausência de evidência de pensamentos acelerados (item 31) e de aumento da sociabilidade (item 53) e o predomínio de sintomas psicóticos, apesar da ocorrência de perturbação afetiva ocasional

Tabela 1 - Diferenças entre as três simulações do diagnóstico de John Nash pelo OPCRIT

\begin{tabular}{lcclc}
\hline \multicolumn{1}{c}{ Parâmetro clínico } & Item & \multicolumn{3}{c}{ Simulação } \\
\cline { 3 - 5 } & & \multicolumn{1}{c}{$\begin{array}{c}\text { Sem evidência suficiente } \\
\begin{array}{l}\text { Presença de } \\
\text { pensamentos acelerados }\end{array}\end{array}$} & $\begin{array}{l}\text { Suração de 2 semanas ou } \\
\text { mais }\end{array}$ & $\begin{array}{l}\text { Duração de 2 semanas ou } \\
\text { mais }\end{array}$ \\
$\begin{array}{l}\text { Ocorrência de aumento } \\
\text { de sociabilidade }\end{array}$ & 53 & Sem evidência suficiente & $\begin{array}{l}\text { Sim, tempo não } \\
\text { especificado }\end{array}$ & $\begin{array}{l}\text { Sim, tempo não } \\
\text { especificado }\end{array}$ \\
$\begin{array}{l}\text { Balanço entre sintomas } \\
\text { psicóticos e de humor }\end{array}$ & 52 & Predomínio de psicose & $\begin{array}{l}\text { Equivalência de sintomas, Predomínio de psicose } \\
\text { porém com 2 semanas ou } \\
\text { mais só com psicose }\end{array}$ \\
\hline
\end{tabular}


(item 52). Na Simulação 2, considerou-se a ocorrência de pensamentos acelerados (item 31) e aumento da sociabilidade (item 53), ambos por pelo menos 2 semanas. Além disso, atribuiu-se o equilíbrio de sintomas afetivos e psicóticos, mas sem nenhum grupo de sintomas dominando o curso global da doença, porém com delírios e alucinações durando pelo menos 2 semanas e "sem predominância de sintomas de humor" (item 52). Por fim, na Simulação 3, foi mantida a presença de pensamentos acelerados (item 31) e sociabilidade aumentada (item 53), mas "com sintomas psicóticos dominando o quadro clínico" (item 52).

\section{RESULTADOS}

Os diagnósticos obtidos nas Simulações 1 e 3 foram de esquizofrenia conforme o DSM-IV e esquizofrenia indiferenciada conforme a CID10, corroborando o diagnóstico descrito na biografia de John Nash. A Simulação 2 apresentou os diagnósticos de transtorno esquizoafetivo tipo bipolar de acordo com o
DSM-IV e de transtorno esquizoafetivo tipo maníaco pela CID-10 (tabela 2).

O que se observa pelas diferentes simulações é que variações nos sintomas de pensamentos acelerados (item 31) e de aumento de sociabilidade (item 53) (freqüentemente presentes na mania) não são suficientes para mudar o diagnóstico de esquizofrenia para transtorno esquizoafetivo. No entanto, a simples mudança do critério de proporcionalidade entre sintomas psicóticos e afetivos (item 52), da alternativa inicial "predomínio de sintomas psicóticos no quadro clínico, embora também podendo ocorrer perturbação afetiva ocasional" (código 1) para a alternativa "equilíbrio entre sintomas psicóticos e afetivos, com nenhum grupo de sintomas dominando o curso da doença, porém com delírios e alucinações durante pelo menos 2 semanas, mas sem sintomas de humor proeminentes" (código 4), muda o diagnóstico, tanto pelo DSM-IV como pela CID-10, de esquizofrenia para transtorno esquizoafetivo. Assim, a ocorrência de dois sintomas de humor

Tabela 2 - Diagnósticos obtidos pelo OPCRIT conforme as três simulações

\begin{tabular}{|c|c|c|c|}
\hline & Simulação 1 & Simulação 2 & Simulação 3 \\
\hline DSM-IV & Esquizofrenia & $\begin{array}{l}\text { Transtorno esquizoafetivo tipo } \\
\text { bipolar }\end{array}$ & Esquizofrenia \\
\hline CID-10 & Esquizofrenia indiferenciada & $\begin{array}{l}\text { Transtorno esquizoafetivo tipo } \\
\text { maníaco }\end{array}$ & Esquizofrenia indiferenciada \\
\hline DSM-III & Esquizofrenia & Psicose atípica & Esquizofrenia \\
\hline DSM-III-R & Esquizofrenia & $\begin{array}{l}\text { Transtorno esquizoafetivo tipo } \\
\text { bipolar }\end{array}$ & Esquizofrenia \\
\hline $\mathrm{RDC}$ & $\begin{array}{l}\text { Transtorno esquizoafetivo } \\
\text { maníaco }\end{array}$ & $\begin{array}{l}\text { Transtorno esquizoafetivo tipo } \\
\text { maníaco }\end{array}$ & $\begin{array}{l}\text { Transtorno esquizoafetivo tipo } \\
\text { maníaco }\end{array}$ \\
\hline St. Louis & $\begin{array}{l}\text { Esquizofrenia com transtorno de } \\
\text { humor sec. - mania }\end{array}$ & & $\begin{array}{l}\text { Esquizofrenia com transtorno de } \\
\text { humor sec. - mania }\end{array}$ \\
\hline Carpenter & Esquizofrenia & Esquizofrenia nível 6 & Esquizofrenia nível 6 \\
\hline Schneider & $\begin{array}{l}\text { Esquizofrenia de primeira } \\
\text { ordem }\end{array}$ & $\begin{array}{l}\text { Esquizofrenia de primeira } \\
\text { ordem }\end{array}$ & $\begin{array}{l}\text { Esquizofrenia de primeira } \\
\text { ordem }\end{array}$ \\
\hline $\begin{array}{l}\text { Critérios } \\
\text { Franceses }\end{array}$ & Esquizofrenia crônica & Esquizofrenia crônica & Esquizofrenia crônica \\
\hline Taylor \& Abrams & & Mania & \\
\hline Tsuang \& Winokur & Esquizofrenia hebefrênica & Esquizofrenia hebefrênica & Esquizofrenia hebefrênica \\
\hline Crow & Misto & Misto & Misto \\
\hline Farmer & Esquizofrenia tipo $\mathrm{H}$ & Esquizofrenia tipo $\mathrm{H}$ & Esquizofrenia tipo $\mathrm{H}$ \\
\hline
\end{tabular}


adicionais em um período de tempo não se mostrou tão importante quanto a observação da evolução do transtorno ao longo do tempo, o que permitiu o registro adequado do balanço entre sintomas de humor e de psicose. $O$ registro alterado do balanço entre sintomas de humor e psicose pode levar a mudanças de diagnóstico nos dois principais sistemas classificatórios (DSM-IV e CID-10). Por outro lado, a codificação adicional da presença de delírios de grandiosidade, aceleração do pensamento e desinibição com inadequação social, porém com duração menor que os demais sintomas psicóticos, não só preservou o diagnóstico de esquizofrenia como também reforçou os relatos de clínicos experientes, de que alguns sintomas podem ocorrer nas categorias diagnósticas esquizofrenia, transtorno esquizoafetivo e transtorno de humor bipolar, como a presença de delírios com componentes bizarros, que não é específica a uma das três, devendo, portanto, ser encarada com cautela na definição do diagnóstico.

\section{DISCUSSÃO}

Progressivamente têm aumentado o conhecimento sobre as diferenças conceituais nos diversos sistemas de classificação utilizados e, conseqüentemente, as dificuldades de validade e confiabilidade. Os sistemas mais conhecidos (DSM-IV e CID-10) são os que apresentam maior confiabilidade e bons índices de concordância $(k a p p a=0,823)^{14}$, apesar de nenhum ter passado por um processo completo de validação. Esses sistemas corroboram o diagnóstico de esquizofrenia na maior parte dos critérios, como tipo e duração dos sintomas e critérios de exclusão ${ }^{15}$. Discordam, porém, quanto aos critérios de curso da doença, duração total de observação necessária para o diagnóstico e impacto sobre a vida do paciente (tabela 3).

$\mathrm{Na}$ classificação de transtorno esquizoafetivo, observa-se que existe uma discrepância sutil entre o DSM-IV e a CID-10 (tabela 4). Os sintomas coincidem em três pontos: 1) necessidade da presença de

Tabela 3 - Comparação entre os critérios diagnósticos para esquizofrenia do DSM-IV e CID-10

\begin{tabular}{|c|c|c|c|}
\hline Critérios & Descrição & DSM-IV & CID-10 \\
\hline \multirow{5}{*}{$\begin{array}{l}\text { Um dos sintomas por } 1 \text { mês } \\
\text { ou mais }\end{array}$} & (a) Eco do pensamento, inserção, roubo, irradiação & $X$ & $X$ \\
\hline & (b) Delírios: controle, influência, passividade & & $X$ \\
\hline & (c) Vozes comentadoras: entre si, originadas do corpo & $x$ & $\mathrm{X}$ \\
\hline & (d) Delírios inapropriados culturalmente, impossíveis & $X$ & $X$ \\
\hline & (e) Delírios bizarros & $X$ & \\
\hline \multirow{4}{*}{$\begin{array}{l}\text { Dois sintomas por } 1 \text { mês ou } \\
\text { mais }\end{array}$} & (a) Alucinações de outra modalidade + delírios não-afetivos & $x$ & $X$ \\
\hline & $\begin{array}{l}\text { (b) Neologismos, interceptações, interpolação de curso do } \\
\text { pensamento, discurso incoerente ou irrelevante }\end{array}$ & $x$ & $X$ \\
\hline & $\begin{array}{l}\text { (c) Comportamento catatônico: excitação, flexibilidade cérea, } \\
\text { negativismo, mutismo, estupor }\end{array}$ & $x$ & $\mathrm{X}$ \\
\hline & $\begin{array}{l}\text { (d) Sintomas negativos: apatia, pobreza de discurso, embotamento, } \\
\text { incongruência de respostas emocionais }\end{array}$ & $x$ & $\mathrm{X}$ \\
\hline Curso & Disfunção social/ocupacional (muito abaixo do prévio) & $X$ & * \\
\hline Duração & Sinais continuados por 6 meses (prodrômicos e residuais) & $X$ & \\
\hline \multirow[t]{2}{*}{ Exclusão } & Doença cerebral, intoxicação, dependência, abstinência & & $X$ \\
\hline & $\begin{array}{l}\text { Mania/depressão (critérios de sintomas preenchidos antes da } \\
\text { alteração de humor) }\end{array}$ & & $x$ \\
\hline
\end{tabular}

\footnotetext{
* Opcional, com observação de pelo menos 1 ano.
} 
sintomas de humor por período de tempo substancial e em número suficiente para preencher o diagnóstico de transtorno de humor; 2) exigência de sintomas de pelo menos um grupo de sintomas de psicose por pelo menos 2 semanas; e 3) necessidade de exclusão de diagnósticos de transtornos orgânicos e relacionados a substâncias. Entretanto, o DSM-IV exige um período de psicose sem alteração de humor ocorrendo por pelo menos 2 semanas, enquanto a CID-10 exige uma equivalência entre número, gravidade e duração de sintomas de humor e de psicose durante a maior parte da doença.

Essas sutis diferenças de balanço entre sintomas de humor e psicose revelam incertezas diagnósticas, podendo acarretar diferentes diagnósticos para casos de pacientes com mescla de sintomas psicóticos e de humor, como ocorre com freqüência na prática clínica, como ocorreu historicamente com John Nash, através de sua passagem por diferentes psiquiatras, e como foi observado nas três simulações com sintomas de difícil consenso.

Devido à alta freqüência deste tipo de dificuldade diagnóstica na prática clínica, motivada pela ausência de validação formal de diagnóstico, apesar de alta confiabilidade, pode-se pensar na expansão do uso de sistemas classificatórios com critérios operacionais e algoritmos definidos por computador, como é o caso do sistema OPCRIT, para apoio ao diagnóstico clínico e melhor orientação na tomada de decisão baseada em evidências, uma vez que o diagnóstico desses casos de psicose e humor alterado pode ser considerado uma "opinião", como disse Kety ${ }^{16}$. Já que não se sabe bem "que coisa" está sendo diagnosticada, progressivamente tem aumentado a evidência de concomitância não só de sintomas de humor e psicose, como também de agregação de diagnósticos de transtornos esquizofrênicos, esquizoafetivos e de humor em famílias ${ }^{17}$. Uma das alternativas para enfrentar tais dificuldades é o uso de sistemas capazes de lidar com uma lista ampla de sintomas, com glossário e ocorrência temporal de intensidade bem definidos e gerando diagnósticos dentro de diferentes sistemas de classificação. O uso de sistemas polidiagnósticos baseados em algoritmos pode auxiliar clínicos e pesquisadores na área, superando a questão de opção de uso de um sistema em detrimento de outro. No caso, o sistema OPCRIT gerou diagnósticos confiáveis com alta concordância em três diferentes simulações.

Tabela 4 - Comparação entre os critérios diagnósticos para transtorno esquizoafetivo do DSM-IV e CID-10

\begin{tabular}{|c|c|c|c|}
\hline Critérios & Descrição & DSM-IV & CID-10 \\
\hline \multirow{2}{*}{$\begin{array}{l}\text { Relação sintomas psicóticos } \\
\text { e de humor }\end{array}$} & Concomitância em um momento & $\mathrm{X}$ & \\
\hline & Concomitância em frequêencia, gravidade e duração & & $X$ \\
\hline Sintomas de humor & Período substancial da doença & $x$ & $X$ \\
\hline \multirow{6}{*}{$\begin{array}{l}\text { Sintomas de um grupo de } \\
\text { psicose por } 2 \text { semanas ou } \\
\text { mais }\end{array}$} & (a) Eco, inserção, roubo, irradiação do pensamento & $X$ & $X$ \\
\hline & (b) Delírios de controle, influência, passividade & $x$ & $x$ \\
\hline & (c) Vozes comentadoras, discutindo, originadas no corpo & $X$ & $X$ \\
\hline & $\begin{array}{l}\text { (d) Delírios persistentes inapropriados, impossíveis (não só } \\
\text { grandiosos) }\end{array}$ & $x$ & $X$ \\
\hline & (e) Discurso incoerente, irrelevante, neologismo & $\mathrm{X}$ & $X$ \\
\hline & (f) Catatonia freqüente e intermitente & $\mathrm{X}$ & $X$ \\
\hline \multirow{2}{*}{$\begin{array}{l}\text { Duração de sintomas } \\
\text { psicóticos e de humor }\end{array}$} & Sintomas psicóticos e de humor proeminentes & $\mathrm{X}$ & $X$ \\
\hline & Psicose sem sintomas de humor por pelo menos 2 semanas & $\mathrm{X}$ & \\
\hline Exclusão & Doença cerebral, intoxicação, dependência, abstinência & $X$ & $X$ \\
\hline
\end{tabular}




\section{CONCLUSÕES}

O estudo de simulação diagnóstica a partir dos relatos bibliográfico e cinematográfico de John Nash, com o uso do programa OPCRIT para entrevista e diagnóstico, mostrou-se válido e permitiu um diagnóstico convergente com o de seus médicos. Através do estudo do caso, foi possível verificar a necessidade e importância da avaliação correta de dois grupos de sintomas (delírios grandiosos e idéias aceleradas) e de parâmetros adequados de observação clínica ao longo do tempo, a despeito das diferenças conceituais das classificações correntemente usadas na pesquisa e prática clínica (DSM-IV, CID-10 e outras).

Com base nas evidências das três simulações geradas a partir da ausência de consenso em dois sintomas e no balanço de duração de sintomas, propõe-se a seguir um esquema que descreve os principais pontos a serem considerados durante o diagnóstico de esquizofrenia e transtorno esquizoafetivo.

Sintomas de delírios grandiosos. Deve-se buscar destacar a diferença entre grandiosidade bizarra com agitação e grandiosidade com elação do humor. Entretanto, mesmo que não seja possível uma distinção clara, isto não irá modificar o diagnóstico final, seja pela CID-10 ou pelo DSM-IV.

Sintomas de pensamentos acelerados. Devem ser observados e registrados; no entanto, da mesma forma, sua ocorrência não modificará o diagnóstico.

Observação do curso da doença. A definição precisa da proporção entre sintomas psicóticos e afetivos é de extrema importância para o diagnóstico diferencial entre esquizofrenia e transtorno esquizoafetivo para diferentes sistemas classificatórios, apesar de divergências na avaliação desta proporção. Um pequeno erro de avaliação pode ter conseqüências importantes para o diagnóstico final.

Deve-se buscar formulação polidiagnóstica sempre que possível (pelos diversos sistemas de classificação), uma vez que, mesmo corretamente utilizados, eles podem gerar diagnósticos diferentes sempre que a especificação de intensidade e duração de sintomas divergir.

Acreditamos que a dificuldade diagnóstica ilustrada neste exercício de simulação, levando em conta três situações de ausência de consenso, seja reflexo de um problema mais amplo de validade desses sistemas (CID-10 e DSM-IV) e suas respectivas categorias diagnósticas como entidades clínica e etiologicamente distintas. É possível que existam várias formas intermediárias de psicose com sintomas de humor ou que os dois diagnósticos clássicos de esquizofrenia e transtorno de humor bipolar representem um espectro da mesma doença, ou um tipo de expressão fenotípica incompleta de uma única doença, sem necessariamente implicar resposta a tratamentos diferentes.

Hoje, por exemplo, a importância do uso precoce e continuado de antipsicóticos é reforçada, independentemente do tipo de diagnóstico categórico da psicose (esquizofrenia ou transtorno de humor bipolar com sintomas psicóticos). Desta maneira, é possível que, através do uso precoce e por tempo prolongado dessas drogas, com revisão periódica, possamos prevenir a deterioração, o isolamento, a exclusão e o infortúnio de muitos de nossos pacientes, o que não ocorreria se ficássemos esperando por anos de evolução de uma doença com sintomas de humor e psicose para tratar os pacientes com antipsicóticos e/ou estabilizadores de humor.

A expansão do uso de diagnósticos categóricos em detrimento dos dimensionais trouxe vantagens na comunicação entre clínicos e estatísticos, mas também trouxe o aumento do risco de detectar sintomas e doenças de forma mais imprecisa e grosseira, empobrecendo a observação clínica e a descrição da psicopatologia pela separação das entidades por pontos de corte que possam dar a impressão de distâncias maiores do que as reais. Assim, apesar de parecer que um retorno completo à descrição minuciosa de sintomas para qualquer caso de psicose possa parecer muito custoso e de benefício duvidoso para justificar seu uso no dia-a-dia, ela permite não só a construção progressivamente mais consistente de critérios para a categorização de diagnósticos, como também a complementação das descrições dimensionais, descartando menos informação para o entendimento e o atendimento individual, mantendo a riqueza descritiva e possibilitando a compreensão dos problemas pessoais, familiares e sociais associados às doenças psiquiátricas. Progressivamente, tem sido fortalecida a adequação do uso conjugado de diagnósticos categóricos e dimensionais em doenças graves com psicose, devido a sua vantagem de associar a descrição ao entendimento da experiência de vida ligada à psicose.

Por fim, o estudo reforça a idéia de que a delimitação apressada somente pela sua 
ocorrência de sintomas, sem o balanço preciso do tempo de ocorrência de sintomas psicóticos e de humor, prejudica a confiabilidade do diagnóstico, ao mesmo tempo em que revela as limitações dos conceitos atuais das psicoses como categorias distintas e precisas de doenças. Entretanto, mesmo a descrição detalhada não só não soluciona a questão da conceituação das psicoses como síndromes com dimensões contínuas ou categóricas, mas também intensifica o conflito de conhecimento. Revela também que os transtornos mentais graves não são tão diferentes entre si como se supõe, guardando semelhanças e fronteiras pouco nítidas. Essa fragilidade de fronteiras reforça a necessidade de estudos mais detalhados correlacionando dimensões de sintomas com fatores de risco, desfecho e resposta a tratamento ${ }^{18,19}$.

Este trabalho, associado à determinação de padrões ou dimensões bioquímicas, eletrofisiológicas, moleculares e psicológicas nos portadores de psicose e sintomas de humor, pode contribuir para a definição de uma nova geração de nosografia baseada em causas ou em efeitos de doenças. Isso permite a evolução e o avanço baseado em evidência de causa, curso e resposta ao tratamento a partir da dicotomia instaurada por Kraepelin, ao dividir a psicose nos grandes grupos de demência precoce e insanidade maníaco-depressiva ${ }^{20}$. Com isso, pode-se pensar em uma real evolução da definição das psicoses, com reais utilidades clínicas. Dentro dessa proposta, programas de computadores de assistência ao diagnóstico, como o OPCRIT, aparecem como ferramentas cada vez mais necessárias pela sua simplicidade, praticidade, confiabilidade e operacionalidade, os quais espera-se que venham a ser progressivamente mais utilizados.

\section{REFERÊNCIAS BIBLIOGRÁFICAS}

1. Associação Americana de Psiquiatria Manual diagnóstico e estatístico de transtornos mentais - DSM-

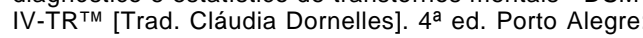
Artmed; 2002.

2. Organização Mundial da Saúde. Classificação de transtornos mentais e de comportamento da CID-10: descrições clínicas e diretrizes diagnósticas. [Trad. Dorival Caetano]. Porto Alegre: Artes Médicas; 1993.

3. Nasar S. Uma mente brilhante. [Trad. Sérgio Moraes Rego]. Rio de Janeiro: Record; 2002.

4. Angst J. Historical aspects of the dichotomy between manic-depressive disorders and schizophrenia. Schizophr Res 2002;57(1):5-13

5. McGuffin P, Farmer A, Harvey I. A polydiagnostic application of operational criteria in studies of psychotic illness. Arch Gen Psychiatry 1991;48:764-70.
6. Mc Guffin P, Farmer A. Polydiagnostic approaches to measuring and classifying psychopathology. Am J Med Genet 2001;105(1):39-41.

7. Soares MJ, Dourado A, Macedo A, Valente J, Coelho I, de Azevedo MHP. Estudo de fidelidade da lista de critérios operacionais para doenças psicóticas Psiquiatria Clínica 1997;18(1):11-24.

8. de Azevedo MHP, Macedo A, Dourado A, Valente J, Coelho I, Soares MJ. Grupo de estudos de genética psiquiátrica: uma década de atividades. Psiquiatria Clínica 2000;21(1):13-22.

9. de Abreu PSB, Hutz MH, Lobato MI, Palha J, Gama C Estudo das bases moleculares da esquizofrenia nas populações brasileira e portuguesa. Cooperação Internacional CAPES-GRICES. [tese]. Porto Alegre: Universidade Federal do Rio Grande do Sul; 2004.

10. Mclntosh AM, Forrester A, Lawrie SM, Byrne M, Harper A, Kestelman JN, et al. A factor model of the functional psychoses and the relationship of factors to clinical variables and the brain morphology. Psychol Med 2001;31(1):159-71.

11. Serreti A, Rietschel M, Lattuada E, Krauss H, Schulze TG, Muller DJ, et al. Major psychoses symptomatology: factor analysis of 2241 psychotic subjects. Eur Arch Psychiatry Clin Neurosci 2001;251(4):193-8.

12. Craddock M, Asherson $P$, Owen MJ, Williams J, McGuffin $P$, Farmer AE. Concurrent validity of the OPCRIT diagnostic system. Comparison of OPCRIT diagnoses with consensus best-estimate lifetime diagnoses. $\mathrm{Br} J$ Psychiatry 1996;169(1):58-63.

13. Azevedo $\mathrm{MH}$, Soares MJ, Coelho I, Dourado A, Valente J, Macedo A, et al. Using consensus OPCRIT diagnoses. An efficient procedure for best-estimate lifetime diagnoses. Br J Psychiatry 1999;175:154-7.

14. Williams J, Farmer AE, Ackenheil M, Kaufmann CA, et al. A multicentre inter-rater reliability study using the OPCRIT computerized diagnostic system. Psychol Med 1996;26:775-83.

15. de Abreu PSB, Gil A. Esquizofrenia. In: Neto AC, Gauer GJC, Furtado NR, eds. Psiquiatria para estudantes de medicina. Porto Alegre: Edipucrs; 2003. pp. 369-80.

16. Kety SS, Wender PH, Jacobsen B, Ingraham LJ, Jansson $L$, Faber B, et al. Mental illness in the biological and adoptive relatives of schizophrenic adoptees. Replication of the Copenhagen Study in the rest of Denmark. Arch Gen Psychiatry 1994;51:442-55.

17. van Os J, Gilvarry C, Bale R, van Horn E, Tattan T, White I, et al. Diagnostic value of the DSM and ICD categories of psychosis: an evidence-based approach. UK 700 Group. Soc Psychiatry Psychiatr Epidemiol 2000;35(7):305-11.

18. Gil A, de Abreu PSB. Estudo de polimorfismo no gene da dopamina beta-hidroxilase em um subgrupo de esquizofrênicos [dissertação]. Porto Alegre: Universidade Federal do Rio Grande do Sul; 2004.

19. Martins CD, de Abreu PSB. Sintomas de humor em esquizofrenia: associação com história familiar e personalidade pré-mórbida [dissertação]. Porto Alegre: Universidade Federal do Rio Grande do Sul; 2004.

20. Kraepelin E. Psychiatrie. Ein lehrbuch für studierende und ärzte. 6th ed. Leipzig: Johann Ambrosius Barth; 1899.

\section{RESUMO}

Introdução: Utilizamos uma simulação diagnóstica no caso John Nash, Prêmio Nobel de Matemática de 1994 e descrito como portador de esquizofrenia, para apresentar o Inventário de Critérios Operacionais para Doenças Psicóticas 
(OPCRIT) e discutir as frágeis delimitações dos diagnósticos categóricos, bem como o uso de diagnósticos dimensionais em psiquiatria.

Método: Baseados na biografia escrita por Sylvia Nasar e no filme Uma mente brilhante, os autores discutiram a sintomatologia e preencheram o OPCRIT. Devido à ausência inicial de consenso, repetiu-se a simulação mais duas vezes, modificando-se os itens que avaliam a presença de pensamentos acelerados (item 31), a ocorrência de aumento de sociabilidade (item 53) e o balanço entre sintomas psicóticos e de humor (item 52), a fim de verificar as repercussões dessas mudanças no diagnóstico.

Resultados: Os diagnósticos obtidos em duas simulações foram esquizofrenia (DSM-IV) e esquizofrenia indiferenciada (CID-10), corroborando o diagnóstico de John Nash em sua biografia. Outra simulação apresentou os diagnósticos de transtorno esquizoafetivo tipo bipolar (DSM-IV) e transtorno esquizoafetivo tipo maníaco (CID-10). Apenas a mudança do critério de proporcionalidade entre sintomas psicóticos e de humor (item 52) alterou o diagnóstico de esquizofrenia para transtorno esquizoafetivo.

Discussão: As fronteiras que separam os diagnósticos de esquizofrenia e transtorno esquizoafetivo são muito tênues, o que explica a freqüente dificuldade diagnóstica.

Conclusões: Ressaltamos a importância do estudo detalhado do curso da doença, enfatizando o balanço entre sintomas psicóticos e de humor, para a definição diagnóstica dos transtornos psicóticos conforme as classificações atuais. Por fim, destacamos a importância dos diagnósticos dimensionais e a necessidade de mais estudos para a validação das categorias diagnósticas atuais.

Descritores: Diagnóstico, esquizofrenia, OPCRIT, transtorno esquizoafetivo.

\section{ABSTRACT}

Background: A diagnostic simulation exercise was carried out using John Nash's case (the 1994 Mathematics Nobel Prize winner and described as suffering from schizophrenia) to introduce the Operational Criteria Checklist for Psychotic IIIness (OPCRIT) and discuss the uncertain boundaries between some of the diagnostic categories presented by the instrument, as well as the use of dimensional diagnosis in psychiatry.

Methods: Data were obtained from John Nash's biography (written by Sylvia Nasar) and from the movie A Beautiful Mind. The authors discussed the symptoms shown in both the biography and the movie and then entered data into the OPCRIT program. Because consensus was not reached in some items, two additional simulations were carried out. In these, three items were modified, in order to investigate the effects of these changes on diagnosis: thoughts racing (31st item), increased sociability (53rd item), and relationship psychotic/affective symptoms (52nd item).

Results: The diagnoses provided by two of the simulations were schizophrenia (DSM-IV) and undifferentiated schizophrenia (ICD-10). Other results included schizoaffective disorder/bipolar type (DSM-IV) and schizoaffective disorder/manic type (ICD-10). It is important to emphasize that the 52 nd item (relationship psychotic/affective symptoms) was the only one with an effect on diagnosis when altered (schizophrenia vs. schizoaffective disorder).

Discussion: The boundaries between schizophrenia and schizoaffective disorder are not clear and explain the frequent difficulty faced by psychiatrists in establishing diagnosis.

Conclusions: This exercise revealed the importance of a detailed assessment of the course of illness for a correct diagnosis, emphasizing the relationship between psychotic and affective symptoms. We emphasize the importance of dimensional diagnosis and the need for further studies in order to validate the diagnostic categories currently used.

Keywords: Diagnosis, schizophrenia, OPCRIT, schizoaffective disorder.

Title: Mood and psychosis in schizophrenia: exploring diagnostic frontiers with the Operational Criteria Checklist for Psychotic IIIness (OPCRIT) and Jonh Nash case

\section{RESUMEN}

Introducción: Utilizamos una simulación diagnóstica en el caso John Nash, Premio Nobel de Matemática en 1994 y descrito como portador de esquizofrenia, para presentar el Inventario de Criterios Operacionales para las Enfermedades Psicóticas (OPCRIT) y discutir las frágiles delimitaciones de los diagnósticos categóricos y el uso de diagnósticos dimensionales en psiquiatría.

Método: Basados en la biografía escrita por Sylvia Nasar y en la película Una mente maravillosa (A Beautiful Mind), los autores discutirán la sintomatología y completaron el OPCRIT. Debido a la ausencia inicial de consenso, se ha repetido la simulación dos veces más, modificándose los puntos que evalúan la presencia de pensamientos acelerados (ítem 31), la ocurrencia de aumento de sociabilidad (ítem 53) y el equilibrio entre síntomas psicóticos y de ánimo (ítem 52), para verificar las repercusiones en el diagnóstico.

Resultados: Los diagnósticos obtenidos en dos de las simulaciones fueron esquizofrenia (DSM-IV) y esquizofrenia indiferenciada (CID-10), corroborando con el diagnóstico de John Nash en su biografía. La otra simulación presentó los diagnósticos de trastorno esquizoafectivo de tipo bipolar (DSM-IV) y de trastorno esquizoafectivo de tipo maníaco (CID-10). 
Solamente el cambio del criterio de proporcionalidad entre síntomas psicóticos y de ánimo (ítem 52) alteró el diagnóstico de esquizofrenia para trastorno esquizoafectivo.

Discusión: Las fronteras que separan los diagnósticos de esquizofrenia $y$ trastorno esquizoafectivo son muy tenues, lo que explica las dificultades diagnósticas.

Conclusiones: Subrayamos la importancia del estudio detallado del curso de la enfermedad, enfatizando la proporción entre síntomas psicóticos y de ánimo, para la definición diagnóstica de los trastornos psicóticos conforme a las clasificaciones actuales. Además, destacamos la importancia de los diagnósticos dimensionales y la necesidad de más estudios para la validación de las categorías diagnósticas actuales.
Palabras clave: Diagnóstico, esquizofrenia, OPCRIT, trastorno esquizoafectivo

Título: Ánimo y psicosis en esquizofrenia: explorando ronteras diagnósticas con el Inventario de Criterios Operacionales para Enfermedades Psicóticas (OPCRIT) y el caso John Nash

Endereço para correspondência:

Cristiane Damacarena Nunes Martins

Rua Mostardeiro, 333/311

CEP 90430-001 - Porto Alegre - RS

Fone: (51) 3222-9490

Fax: (51) 3222-9490

E-mail: damacarena@cpovo.net

Copyright (C) Revista de Psiquiatria do Rio Grande do Sul - SPRS 


\section{ANEXO 1}

Descrição dos critérios de pontuação do OPCRIT

1. Fonte de avaliação

$1=$ Registros/processos clínicos hospitalares

2 = Entrevista estruturada efetuada com o indivíduo

3 = Sumário preparado

$4=$ Entrevista com o informante

$5=$ Combinação de fontes incluindo entrevista estruturada

6 = Combinação de fontes excluindo entrevista estruturada

2. Período de tempo

1 = Atual/presente ou episódio mais recente

2 = Episódio mais grave que teve

$3=$ Ocorrência em toda a vida de sintomas e sinais

4 = Outro episódio especificado ou período de tempo

3. Código do sexo

$0=$ Masculino

$1=$ Feminino

4. Idade de início

Deve ser dado até o ano mais próximo e define-se como a idade mais precoce com que procurou ajuda médica por razões psiquiátricas ou com que os sintomas começaram a causar tensão subjetiva ou prejuízo no funcionamento. (Registrar idade em anos; exemplo: 35 .)

5. Modo de início

1 = Início súbito definido dentro de horas ou dias

2 = Início agudo definido dentro de 1 semana

$3=$ Início moderadamente agudo definido dentro de 1 mês

4 = Início gradual durante um período de até 6 meses

5 = Início insidioso durante um período maior que 6 meses

Cotar por cima (com pontuação mais baixa) se em dúvida.

6. Solteiro

O indivíduo nunca casou ou (nunca) viveu como se estivesse casado.

$0=$ Casado

$1=$ Solteiro

7. Desempregado

O indivíduo não estava empregado no início como definido acima (item 4). Mulheres que trabalham o dia todo em casa são cotadas como empregadas. Estudantes que freqüentam aulas em período integral de um curso são cotados como empregados.

$0=$ Empregado

$1=$ Desempregado

8. Duração da doença em semanas (máximo: 99)

A duração total da doença inclui incapacidades prodrômicas e residuais assim como a fase ativa da doença. No distúrbio psicótico, sintomas da fase prodrômica e residual são cotados quando forem apresentados, antes ou depois do episódio ativo, dois dos seguintes sintomas: isolamento social; prejuízo social; comportamento marcadamente peculiar ou diferente; marcado prejuízo na higiene pessoal; afeto embotado, superficial ou inapropriado; discurso digressivo, vago ou hiper-elaborado; ideação estranha ou bizarra; e vivências perceptivas fora do normal. 
9. Mau ajustamento pré-mórbido ao trabalho

Refere-se à história de trabalho antes do início da doença. Deve ser cotado (como $=1$ ) se o doente tiver sido incapaz de manter qualquer trabalho durante mais que 6 meses, tiver uma história de mudanças freqüentes de emprego ou tiver sido somente capaz de agüentar um trabalho bem abaixo do esperado pelo seu nível educacional na época do primeiro contato psiquiátrico. Também cotar positivamente um padrão de trabalho doméstico (donas de casa) persistentemente muito mal e insucesso em acompanhar os estudos.

$0=$ bom ajustamento pré-mórbido

1 = mau ajustamento pré-mórbido

10. Mau ajustamento social pré-mórbido

O doente achava difícil iniciar ou manter relações normais, mostrava persistente isolamento social, mantinha-se ensimesmado ou mantinha interesses solitários antes dos sintomas psicóticos.

$0=$ bom ajustamento

$1=$ mau ajustamento

11. Distúrbio de personalidade pré-mórbido

Evidência de distúrbio de personalidade inadequada, esquizóide, esquizotípica, paranóide, ciclotímica, psicopática e/ou sociopática presente desde a adolescência e anterior ao início dos sintomas psicóticos.

$0=$ ausente

$1=$ presente

12. Abuso de álcool/drogas dentro de 1 ano do início de sintomas psicóticos

Abuso de álcool: quando a quantidade é excessiva (julgamento do avaliador), quando ocorrem complicações relacionadas com o álcool durante o ano anterior ao primeiro contato psiquiátrico (deve ser avaliado rigorosamente, pois é critério de exclusão para algumas definições de esquizofrenia).

$0=$ ausente

$1=$ presente

Abuso de drogas: quando drogas não prescritas são repetidamente tomadas ou drogas prescritas são usadas em quantidades excessivas e sem supervisão médica no ano anterior ao primeiro contato psiquiátrico.

$0=$ ausente

$1=$ presente

13. História familiar da esquizofrenia

Clara história de esquizofrenia em parentes de primeiro ou segundo grau.

$0=$ não

$1=\operatorname{sim}$

14. História familiar de outra doença psiquiátrica

Parentes em primeiro ou segundo grau têm outra doença psiquiátrica suficientemente grave para justificar encaminhamento psiquiátrico.

$0=$ não

$1=\operatorname{sim}$

15. Doença cerebral estrutural anterior ao início

Há evidência pelo exame físico e/ou investigações especiais de doença física que pode explicar todos ou a maioria dos sintomas mentais. Isto pode incluir uma lesão cerebral clara (ou lesões), marcada perturbação metabólica ou estado induzido por drogas que sabidamente causam perturbação psicótica, confusão ou alteração do grau de consciência. Anomalias nãoespecíficas (exemplo: alargamento dos ventrículos no TCC) não devem ser incluídas.

$0=$ ausente

$1=$ presente 
16. Claro estressor psicossocial anterior ao início

Ocorreu um acontecimento ameaçador grave ou moderadamente grave antes do início do distúrbio, que é improvável ser resultado do próprio comportamento do indivíduo (isto é, o acontecimento pode ser visto como independente ou incontrolável).

$0=$ ausente

$1=$ presente

17. Comportamento bizarro

Comportamento que é estranho e incompreensível aos outros. Inclui comportamento que pode ser interpretado como uma resposta a alucinações auditivas ou interferência com o pensamento.

$0=$ ausente

$1=$ presente

18. Catatonia

O doente exibe persistentes maneirismos, estereotipias, posturas, catalepsia, aderência automática às instruções, estupor ou excitação que não são explicáveis por alterações afetivas.

$0=$ ausente

$7=$ se presente durante pelo menos uma porção significativa de tempo durante um período de 1 mês (menos se tratado com êxito)

1 = se presente durante qualquer outra duração ou se a duração é desconhecida

19. Atividade excessiva

O doente está marcadamente hiperativo. Isso inclui atividade motora, social e sexual.

$8=$ se a hiperatividade dura pelo menos 2 dias

9 = para uma duração de pelo menos 4 dias

1 = para uma duração de pelo menos 1 semana

2 = para uma duração de pelo menos 2 semanas

20. Atividade perigosa

O doente está excessivamente envolvido em atividades com elevado potencial de conseqüências dolorosas, que não é reconhecido (exemplo: gastos excessivos, indiscrições sexuais, condução perigosa, etc.).

8 = para uma duração de pelo menos 2 dias

$9=$ para uma duração de pelo menos 4 dias

2 = duração de pelo menos 2 semanas

1 = duração de pelo menos 1 semana

21. Distratibilidade

O doente vivencia dificuldades de concentração no que se passa à sua volta porque a atenção é muito facilmente desviada para fatores irrelevantes ou externos.

8 = duração de pelo menos 2 dias

$9=$ duração de pelo menos 4 dias

2 = pelo menos 2 semanas

$1=$ pelo menos 1 semana

22. Necessidade de sono reduzida

O doente dorme menos mas não se queixa de insônia. O tempo extra acordado é habitualmente ocupado com atividades excessivas.

8 = duração de pelo menos 2 dias

$9=$ duração de pelo menos 4 dias

$1=$ pelo menos 1 semana

2 = pelo menos 2 semanas 
23. Atividade agitada

O doente mostra atividade excessiva, tal como excitação motora, torcer as mãos, andar de um lado para o outro, tudo habitualmente acompanhado por uma expressão de angústia mental.

$1=$ se presente por pelo menos 1 semana

2 = se presente por pelo menos 2 semanas

$3=$ se presente por pelo menos 1 mês

24. Atividade lentificada

$O$ doente refere que se sente lentificado e incapaz de se mexer. Outros podem descrever sentimentos subjetivos de retardamento que podem ser notados pelo clínico que o examina.

$1=$ se presente por pelo menos 1 semana

$2=$ pelo menos 2 semanas

$3=$ pelo menos 1 mês

25. Perda de energia/cansaço

Queixa subjetiva de se sentir excessivamente cansado e sem energia.

$1=$ se presente por pelo menos 1 semana

2 = pelo menos 2 semanas

$3=$ pelo menos 1 mês

26. Discurso difícil de entender

Discurso que torna a comunicação difícil por causa da falta de organização lógica ou organização compreensível. Não inclui disartria ou dificuldade em falar.

$0=$ ausente

$1=$ presente

27. Incoerência

A construção gramatical normal das frases se rompeu. Inclui "salada de palavras" e deve ser cotada somente conservadoramente para formas extremas de distúrbio formal do pensamento. $0=$ ausente

7 = se presente durante uma porção significativa de tempo no período de 1 mês (menos se tratado com êxito)

$1=$ presente durante qualquer outra duração ou a duração não está especificada

28. Distúrbio formal do pensamento positivo

O doente tem um discurso fluente mas tende a se comunicar mal devido a neologismos, uso bizarro de palavras, descarrilamento, perda da associação.

$0=$ ausente

7 = se presente durante uma porção significativa de tempo no período de 1 mês (menos se tratado com êxito)

$1=$ presente durante qualquer outra duração ou duração inespecífica

29. Distúrbio formal do pensamento negativo

Inclui pobreza do pensamento, freqüente bloqueio do pensamento, pobreza do discurso ou pobreza do conteúdo do discurso.

$0=$ ausente

$1=$ presente

30. Pressão do discurso

O doente está muito mais falador do que o habitual ou sente-se sob pressão para continuar a falar. Inclui distúrbio formal do pensamento tipo maníaco com associações por sons, jogos de palavras ou rimas.

8 = duração de pelo menos 2 dias

$9=$ duração de pelo menos 4 dias

$1=$ pelo menos 1 semana

2 = pelo menos 2 semanas 
31. Pensamentos acelerados

O doente vivencia os pensamentos que ocorrem em sua cabeça, ou os outros observam fuga de idéias e acham difícil seguir o que o doente está dizendo, ou o interrompem por causa da rapidez e quantidade do discurso.

8 = duração de pelo menos 2 dias

$9=$ pelo menos 4 dias

$1=$ pelo menos 1 semana

2 = pelo menos 2 semanas

32. Restrição do afeto

As respostas emocionais do doente são limitadas em amplitude, e na entrevista há uma impressão de indiferença maliciosa ou de "falta de contato".

$0=$ ausente

7 = presente durante uma porção significativa de tempo no período de 1 mês (menos se tratado com êxito)

1 = presente durante qualquer outra duração ou duração inespecífica

33. Embotamento afetivo

As respostas emocionais do doente são persistentemente sem grande profundidade e mostram uma completa falência em ressoar a mudança exterior. Diferenças entre restrição e embotamento do afeto devem ser consideradas de grau, com embotamento sendo somente cotado em casos extremos.

$0=$ ausente

$7=$ presente durante uma porção significativa de tempo no período de 1 mês (menos se tratado com êxito)

$1=$ presente durante qualquer outra duração ou duração inespecífica

34. Afeto inapropriado

As respostas emocionais do doente são inapropriadas às circunstâncias; por exemplo: rir enquanto se discutem ocorrências dolorosas ou tristes, "risinhos" tolos sem razão aparente.

$0=$ ausente

$7=$ presente durante uma porção significativa de tempo por pelo menos 1 mês (menos se tratado com êxito)

1 = presente durante qualquer outra duração ou duração inespecífica

35. Elevação do humor

O humor predominante do doente é de elação.

$8=$ duração de pelo menos 2 dias

$9=$ duração de pelo menos 4 dias

$1=$ pelo menos 1 semana

2 = pelo menos 2 semanas

Se a elação durou menos de 1 semana, mas o doente foi hospitalizado por doença afetiva, cotar 1.

36. Humor irritável

O humor do doente é predominantemente irritável.

8 = duração de pelo menos 2 dias

$9=$ pelo menos 4 dias

$1=$ pelo menos 1 semana

2 = pelo menos 2 semanas

Se a elação durou menos de 1 semana, mas o doente foi hospitalizado por doença afetiva, cotar 1. 
37. Disforia

Humor persistentemente deprimido ou "pra baixo", humor irritável e triste ou perda difusa do interesse.

$1=$ presente durante pelo menos 1 semana

2 = pelo menos 2 semanas

$3=$ pelo menos 1 mês

38. Variação diurna (humor pior de manhã)

Disforia, humor "pra baixo" e/ou sintomas depressivos associados são piores logo após o acordar, com alguma melhoria (mesmo se somente ligeira) à medida que o dia passa.

$0=$ ausente

$1=$ presente

39. Perda de prazer

Incapacidade difusa de ter prazer em qualquer atividade. Inclui marcada perda de interesse ou perda da libido.

1 = duração de pelo menos 1 semana

$2=$ pelo menos 2 semanas

$3=$ pelo menos 1 mês

40. Diminuição da libido

Redução clara e persistente do interesse ou impulso sexual em comparação com o nível antes do início da doença.

$0=$ ausente

9 = duração de pelo menos 4 dias

$1=$ pelo menos 1 semana

41. Dificuldade de concentração

Queixa subjetiva de ser incapaz de pensar com clareza, tomar decisões, etc.

1 = duração de pelo menos 1 semana

2 = pelo menos 2 semanas

$3=$ pelo menos 1 mês

42. Excessiva autoculpabilização

Sentimentos extremos de culpa e desvalorização. Pode ser de intensidade delirante ("a pior pessoa do mundo").

1 = duração de pelo menos 1 semana

2 = pelo menos 2 semanas

$3=$ pelo menos 1 mês

43. Ideação suicida

Preocupação com pensamentos de morte (não necessariamente a própria). Pensa em suicídio, desejaria estar morto, tentativas de suicídio.

1 = duração de pelo menos 1 semana

2 = pelo menos 2 semanas

$3=$ pelo menos 1 mês

44. Insônia inicial

O doente refere ser incapaz de começar a dormir, permanecendo pelo menos 1 hora acordado.

1 = duração de pelo menos 1 semana

2 = pelo menos 2 semanas

$3=$ pelo menos 1 mês

Cotar este item só se houver informação sobre insônia. 
45. Insônia intermediária (sono fragmentado)

$\mathrm{Na}$ maioria das noites, o sono está perturbado, o doente acorda no meio do sono e tem dificuldade em voltar a adormecer.

$0=$ ausente

$1=$ presente

Cotar este item só se houver informação sobre insônia.

46. Despertar precoce

O doente se queixa de acordar persistentemente pelo menos 1 hora mais cedo que a hora habitual de acordar.

1 = duração de pelo menos 1 semana

2 = pelo menos 2 semanas

$3=$ pelo menos 1 mês

47. Sonolência excessiva

$O$ doente se queixa de dormir em demasia.

1 = duração de pelo menos 1 semana

$2=$ pelo menos 2 semanas

$3=$ pelo menos 1 mês

48. Diminuição do apetite

O doente tem queixas subjetivas de diminuição do apetite (não necessariamente se observa comer menos).

1 = duração de pelo menos 1 semana

2 = pelo menos 2 semanas

$3=$ pelo menos 1 mês

49. Perda de peso

$1=$ perda de $500 \mathrm{~g}$ por semana durante várias semanas

2 = perda de pelo menos $1 \mathrm{~kg}$ por semana durante várias semanas

3 = perda de pelo menos $5 \mathrm{~kg}$ durante o período de 1 ano

Não cotar as perdas de peso consecutivas a dietas voluntárias para emagrecer.

50. Aumento do apetite

O doente descreve aumento do apetite e/ou "comer reconfortante".

1 = duração de pelo menos 1 semana

2 = pelo menos 2 semanas

$3=$ pelo menos 1 mês

51. Aumento de peso

1 = aumento de $500 \mathrm{~g}$ por semana durante várias semanas

2 = aumento de pelo menos $1 \mathrm{~kg}$ por semana durante várias semanas

3 = aumento de pelo menos $5 \mathrm{~kg}$ durante o período de 1 ano

52. Relação sintomas psicóticos/afetivos (item decisivo para diagnóstico; preencher com cuidado)

$0=$ sem/não co-ocorrência

1 = os sintomas psicóticos dominam o quadro clínico, embora possa ocorrer também perturbação afetiva ocasional

2 = os sintomas psicóticos e afetivos estão equilibrados; nenhum grupo de sintomas domina o curso global da doença

$3=$ os sintomas afetivos predominam, embora possam também ocorrer sintomas psicóticos

4 = como na cotação 2 (ver acima), mais delírios ou alucinações durante pelo menos 2 semanas, mas sem sintomas do humor proeminentes 
53. Aumento da sociabilidade

$1=$ excessiva familiaridade

2 = perda das inibições sociais, resultando em comportamento inadequado às circunstâncias e que não é próprio do seu caráter (duração de pelo menos 1 semana)

$9=$ um (excessiva familiaridade) ou outro (perda das inibições sociais), quando ocorrem durante pelo menos 4 dias e menos que 1 semana

54. Delírios persecutórios

Inclui todos os delírios com ideação persecutória.

$0=$ ausente

$1=$ presente

Ao cotar delírios, cotar cada um separadamente em uma categoria, descrevendo o tipo específico de delírio (persecutório, grandioso, influência/referência, bizarro, passividade, percepção delirante primária, outros delírios primários, roubo do pensamento, culpa, pobreza ou niilístico).

55. Delírios bem sistematizados

A doença é caracterizada por uma série de delírios bem organizados ou bem sistematizados.

$0=$ ausente

7 = presente durante uma porção significativa de tempo no período de 1 mês (menos se tratado com êxito)

$1=$ presente durante qualquer outra duração ou duração inespecífica

56. Aumento da auto-estima

O doente acredita que é uma pessoa excepcional, com poderes, planos, talentos ou capacidades especiais. Cotar positivamente aqui se idéia sobrevalorizada, mas se a qualidade é delirante, cotar também o item 57 (delírios de grandeza).

8 = duração de pelo menos 2 dias

$9=$ pelo menos 4 dias

$1=$ pelo menos 1 semana

2 = pelo menos 2 semanas

57. Delírio de grandeza

O doente tem um exagerado sentimento da sua importância, tem poderes ou capacidades excepcionais ou acredita que é rico ou famoso, nobre ou parente de pessoas importantes. Inclui também delírios de identificação com Deus, anjos, o Messias, etc. (ver também item 56).

8 = duração de pelo menos 2 dias

$9=$ pelo menos 4 dias

$1=$ pelo menos 1 semana

2 = pelo menos 2 semanas

7 = presente durante uma porção significativa de tempo no período de 1 mês (menos se tratado com êxito)

58. Delírio de influência

Os acontecimentos, objetos ou pessoas do ambiente circundante do doente têm um significado especial, freqüentemente de natureza persecutória. Inclui idéias de referência provenientes da televisão, rádio ou jornais, sendo que o doente acredita que esses órgãos de informação fornecem instruções ou prescrevem certos comportamentos.

$0=$ ausente

7 = presente durante uma porção significativa de tempo no período de 1 mês (menos se tratado com êxito)

$1=$ presente durante qualquer outra duração ou duração inespecífica 
59. Delírios bizarros

Delírios estranhos, absurdos ou fantásticos cujo conteúdo pode ter uma qualidade mística, mágica ou de ficção científica.

$0=$ ausente

$7=$ presente durante uma porção significativa de tempo no período de 1 mês (menos se tratado com êxito)

1 = presente durante qualquer duração ou duração não está especificada

60. Delírios espalhados

Delírios que se alastram à maioria dos aspectos da vida do doente e/ou preocupam-no durante a maior parte do tempo.

$0=$ ausente

7 = presente por uma porção significativa de tempo no período de 1 mês (menos se tratado com êxito)

$1=$ presente durante qualquer outra duração ou duração inespecífica

Este item deve ser cotado em adição à cotação dos tipos de delírios descritos.

61. Delírios de passividade

Inclui todas as sensações, emoções ou ações fabricadas. Inclui todas as vivências de influência em que o doente sabe que seus impulsos, sentimentos, atos ou sensações somáticas são controlados ou impostos por um agente externo.

$0=$ ausente

7 = presente durante uma porção significativa de tempo no período de 1 mês (menos se tratado com êxito)

$1=$ presente durante qualquer outra duração ou duração inespecífica

62. Percepção delirante primária

O doente percebe alguma coisa no ambiente externo que desencadeia uma crença especial, relativamente significativa, incompreensível, da qual está certo e que de algum modo está vagamente ligada com a percepção desencadeante.

$0=$ ausente

$7=$ presente durante uma porção significativa de tempo no período de 1 mês (menos se tratado com êxito)

1 = presente durante qualquer outra duração ou duração inespecífica

63. Outros delírios primários

Inclui humor delirante e idéias delirantes.

O humor delirante é um humor estranho em que o ambiente parece mudado de uma forma ameaçadora, mas o significado da mudança não pode ser compreendido pelo doente, que geralmente está tenso, ansioso ou baralhado. Pode levar a uma crença delirante. Uma idéia delirante surge subitamente na mente do doente completamente formada e não anunciada por quaisquer pensamentos relacionados.

$0=$ ausente

$7=$ presente durante uma porção significativa de tempo no período de 1 mês (menos se tratado com êxito)

1 = presente durante qualquer outra duração ou duração inespecífica

64. Delírios e alucinações que duram 1 semana

Qualquer tipo de delírio acompanhado por qualquer tipo de alucinação durando 1 semana.

$0=$ ausente

7 = presente durante uma porção significativa de tempo no período de 1 mês (menos se tratado com êxito)

$1=$ presente durante qualquer outra duração ou duração inespecífica

Este item deve ser cotado em adição à cotação dos tipos de delírios descritos. 
65. Alucinações e delírios persecutórios/ciúme

Este item se explica por si mesmo. Notar que as crenças anormais são de intensidade e qualidade delirantes e são acompanhadas de alucinações verdadeiras.

$0=$ ausente

$7=$ presente durante uma porção significativa de tempo no período de 1 mês (menos se tratado com êxito)

1 = presente durante qualquer outra duração ou duração não está especificada

Este item deve ser cotado em adição à cotação dos tipos de delírios descritos.

66. Inserção do pensamento

O doente reconhece que os pensamentos estão sendo colocados na sua cabeça, não sendo reconhecidos como seus e tendo sido provável ou claramente inseridos por um agente externo.

$0=$ ausente

$7=$ presente durante uma porção significativa de tempo no período de 1 mês (menos se tratado com êxito)

$1=$ presente durante qualquer outra duração ou duração inespecífica

67. Roubo do pensamento

O doente vivencia paragem dos pensamentos na sua cabeça, o que pode ser interpretado como sendo os pensamentos retirados (ou roubados) por algum agente externo.

$0=$ ausente

$7=$ presente durante uma porção significativa de tempo no período de 1 mês (menos se tratado com êxito)

1 = presente durante qualquer outra duração ou duração não está especificada

68. Difusão do pensamento

O doente vivencia difusão do pensamento para fora de sua cabeça, de modo que podem ser compartilhados pelos outros ou até vividos por outros.

$0=$ ausente

$7=$ presente durante uma porção significativa de tempo no período de 1 mês (menos se tratado com êxito)

1 = presente durante qualquer outra duração ou duração não está especificada

69. Delírios de culpa

Crença firme mantida pelo doente de ter cometido algum pecado, crime ou ter causado dano a outros, apesar da inexistência de qualquer evidência objetiva em apoio dessa crença.

$0=$ ausente

$1=$ presente

70. Delírios de pobreza

Crença firme mantida pelo paciente de ter perdido todo ou muito do seu dinheiro ou bens e ter ficado pobre, apesar da inexistência de qualquer evidência objetiva em apoio dessa crença.

$0=$ ausente

$1=$ presente

71. Delírios niilísticos

Crença firmemente mantida de que alguma parte do corpo do doente tenha desaparecido, apodrecido ou esteja afetada por alguma doença devastadora ou maligna, apesar da inexistência de qualquer evidência objetiva em apoio dessa crença.

$0=$ ausente

$1=$ presente 
72. Eco do pensamento

Cotar 1 se o doente vivencia pensamentos repetidos ou ecoados na sua cabeça ou de uma voz fora de sua cabeça.

$0=$ ausente

$1=$ presente

73. Alucinações auditivas na terceira pessoa

Duas ou mais vozes dialogando sobre o doente na terceira pessoa. Cotar se "verdadeiras" ou "pseudo-alucinações", isto é, a diferenciação da origem das vozes não é importante.

$0=$ ausente

7 = presente durante uma porção significativa de tempo no período de 1 mês (menos se tratado com êxito)

1 = presente durante qualquer outra duração ou duração não está especificada

74. Vozes comentadoras das atividades

O doente ouve vozes que descrevem suas ações, sensações ou emoções à medida que ocorrem. Cotar quer estas sejam possíveis "pseudo-alucinações" ou claras alucinações (verdadeiras).

$0=$ ausente

$7=$ presente durante uma porção significativa de tempo no período de 1 mês (menos se tratado com êxito)

1 = presente durante qualquer outra duração ou duração não está especificada

75. Vozes insultórias/insultantes/acusatórias/persecutórias

Vozes que falam para o doente de modo insultuoso, acusatório ou persecutório.

$0=$ ausente

7 = presente durante uma porção significativa de tempo no período de 1 mês (menos se tratado com êxito)

1 = presente durante qualquer outra duração ou duração não está especificada

76. Outras alucinações auditivas (não-afetivas)

Qualquer outro tipo de alucinação auditiva. Inclui vozes agradáveis ou neutras e alucinações não verbais.

$0=$ ausente

$7=$ presente durante uma porção significativa de tempo no período de 1 mês (menos se tratado com êxito)

1 = presente durante qualquer outra duração ou duração não está especificada

77. Alucinação não-afetiva de qualquer modalidade

Alucinações nas quais o conteúdo não tem relação aparente com elação ou depressão.

$0=$ ausente

7 = presente durante uma porção significativa de tempo no período de 1 mês (menos se tratado com êxito)

1 = presente durante qualquer outra duração ou duração não está especificada

78. Diagnóstico em toda a vida de abuso/dependência de álcool

Uso continuado, apesar do conhecimento de ter um problema persistente ou recorrente social, ocupacional, psicológico ou físico que é causado ou exacerbado pelo uso de álcool; ou uso recorrente em situações nas quais é fisicamente prejudicial; ou sintomas claramente indicativos de dependência. Um dos supracitados deve ter ocorrido persistentemente durante pelo menos 1 mês; ou repetidamente durante um período mais longo.

$0=$ não

$1=\operatorname{sim}$ 
79. Diagnóstico em toda a vida de abuso/dependência de Cannabis

Uso continuado apesar do conhecimento de ter um problema persistente ou recorrente social, ocupacional, psicológico ou físico que é causado ou exacerbado pelo uso de Cannabis; ou uso recorrente em situações nas quais é fisicamente prejudicial; ou sintomas claramente indicativos de dependência. Um dos supracitados deve ter ocorrido persistentemente durante pelo menos 1 mês; ou repetidamente durante um período mais longo.

$0=$ não

$1=\operatorname{sim}$

80. Diagnóstico em toda a vida de abuso/dependência de outras substâncias

Uso continuado apesar do conhecimento de ter um problema persistente ou recorrente social, ocupacional, psicológico ou físico que é causado ou exacerbado pelo uso de outras substâncias; ou uso recorrente em situações nas quais é fisicamente prejudicial; ou sintomas claramente indicativos de dependência. Um dos supracitados deve ter ocorrido persistentemente durante pelo menos 1 mês; ou repetidamente durante um período mais longo.

$0=$ não

$1=\operatorname{sim}$

81. Abuso/dependência de álcool com psicopatologia

Abuso ou dependência como definido no item 78 acompanhado por qualquer dos itens precedentes que descrevem psicopatologia.

$0=$ não

$1=\operatorname{sim}$

82. Abuso/dependência de Cannabis com psicopatologia

Abuso ou dependência como definido no item 79 acompanhado por qualquer dos itens precedentes que descrevem psicopatologia.

$0=$ não

$1=\operatorname{sim}$

83. Abuso/dependência de outras substâncias com psicopatologia

Abuso ou dependência como definido no item 80 acompanhado por qualquer dos itens precedentes que descrevem psicopatologia.

$0=$ não

$1=\operatorname{sim}$

84. Informação não-credível

O doente dá respostas enganadoras às questões ou fornece um relato salgalhado, incoerente ou inconsciente.

$0=$ não

$1=\operatorname{sim}$

85. Ausência de insight

O doente é incapaz de reconhecer que as suas vivências são anormais ou que são produto de processos mentais anômalos, ou reconhece que as suas vivências são anormais, mas dá uma explicação delirante.

1 = ausência de insight

$0=$ presença de insight

86. Contato difícil

O entrevistador tem dificuldade em estabelecer contato com o doente, que parece distante ou alheio. Não incluir doentes que são difíceis de entrevistar devido a hostilidade ou irritabilidade.

$0=$ não

$1=\operatorname{sim}$ 
87. Prejuízo/incapacidade durante o distúrbio

0 = sem prejuízo

1 = prejuízo subjetivo no trabalho, escola ou funcionamento social

2 = prejuízo no papel mais importante da vida, com clara redução na produtividade e/ou foi criticado por isso

3 = não funcionou nada no papel mais importante da vida durante mais de 2 dias ou foi requerida a internação, ou ocorreram sintomas psicóticos ativos, tais como delírios ou alucinações

88. Deterioração do nível de funcionamento pré-mórbido

O doente não recupera o nível de funcionamento social, ocupacional ou emocional pré-mórbido após um episódio agudo da doença.

$0=$ ausente

$1=$ presente

89. Os sintomas psicóticos respondem aos neurolépticos

Avaliar globalmente o período total. Cotar positivamente se a doença parece responder a qualquer tipo de neuroléptico (depot ou oral) ou se ocorre recaída quando a medicação é suspensa.

$0=$ não

$1=\operatorname{sim}$

90. Curso da doença

1 = Episódio único com boa recuperação

4 = Doença crônica contínua

2 = Episódios múltiplos com boa recuperação entre eles

5 = Doença crônica contínua com deterioração

3 = Episódios múltiplos com recuperação parcial entre eles

Cotar este item em sentido hierárquico; por exemplo: se o curso da doença no passado foi cotado 2 , mas se no presente for 4 , então a cotação correta é 4 . 